\title{
Comparison of identification of Enterobacteriaceae by API 20E and Sensititre Autoidentification System
}

\author{
J G BARR, G M HOGG, E T M SMYTH, A M EMMERSON Department of Bacteriology, Royal \\ Victoria Hospital, Belfast, Northern Ireland
}

SUMMARY Of 251 isolates of the Enterobacteriaceae identified to species level by API 20E, 208 (83\%) were similarily identified by the Sensititre Autoidentification System. Both systems shared a common problem in that discrimination between species of the genera Klebsiella, Enterobacter, and Serratia was poor. The eight digit biocode generated by the Sensititre system for individual isolates is not reproducible and therefore not of epidemiological value.

The identification of the Enterobacteriaceae by several commercial systems has been widely adopted in medical bacteriology laboratories over the past decade. Of these systems, API 20E (API System SA, Montalier, France), Minitek (BBL Microbiology systems, Cockeysville, Maryland, USA), Enterotube II (Roche Diagnostics, Welwyn Garden City, Hertfordshire) have been evaluated the most often and their precision compared..$^{1-3}$ These systems are essentially manual and are based on conventional biochemical tests for the discrimination of organisms of the Enterobacteriaceae group. API 20E has become the most widely adopted system after comparative evaluations ${ }^{1-3}$ and may now be seen as a standard comparable with the conventional methods on which it is based. ${ }^{2}$

More recently, automation of identification methods has been developed to include the dispensing of inocula, test reading, and the interpretation of results by reference to microprocessor databases. Of these systems, Autoscan-4 (Microscan Inc., Mahwah, New Jersey, USA), ${ }^{4}$ Sceptor System (BBL Microbiology Systems, Cockeysville, Maryland, USA), ${ }^{s}$ and Titertek-Enterobac-Rapid Automated System (TTE-RAS; Flow Laboratories GmbH, Meckenheim, Federal Republic of Germany) ${ }^{5}$ are automated systems which continue to be based on conventional biochemical substrates and reactions, and which use photometric methods for reading test results. The Sensititre Autoidentification System (Crawley, England) differs from these systems on the basis of its use of a fluorospectrophotometric detection system and the incorporation of several novel substrates for discrimination of the Enterobacteriaceae. ${ }^{6}$ Several previous investigations have reported on the identification of Enterobacteriaceae using

Accepted for publication 12 January 1989
Sensititre equipment, but have not evaluated a fully automated system based on the use of fluorogenic substrates (Proceedings of the Fourth International Symposium on Rapid Methods and Automation in Microbiology and Immunology, Berlin, 1984).

The automated Sensititre system uses an autoinoculator of microtitre plates which are read after incubation, without reagent addition, by an autoreading fluorospectrophotometer linked to a Digital PRO 380 microcomputer. The study reported here compares the identification of clinical isolates of oxidase negative fermentative rods by API $20 \mathrm{E}$ and the Sensititre Autoidentification System.

\section{Material and methods}

Two hundred and seventy four isolates of oxidase negative fermentative bacilli were examined. The isolates were from clinical specimens and were derived from urine $(n=197)$ blood $(n=37)$, sputum $(n=10)$, wounds $(n=16)$ and other sources $(n=14)$.

\section{IDENTIFICATION METHODS}

The API 20E procedure was followed according to the manufacturer's instructions. The Sensititre system uses 32 biochemical tests. These include 23 conventional test substrates: xylose, maltose, arabinose, malonate, urea, trehalose, fructose, formate, ribose, pyruvate, alginate, sucrose, inositol, aesculin, raffinose, citrate, sorbitol, mannitol, arabitol, cellobiose, agmatine, p-nitrophenyl- $\beta$ D-galactopyranoside tryptophane, and an additional nine fluorogenic tests composed of a quenched fluorophore linked to one of nine enzyme substrates. The detection of microbial metabolism is based on a change in fluorescence in end product. Different bases were used for different substrates for the generation of a detectable change in fluorescence. These methods included 
pH shift, enzyme cleavage of quench fluorophores, colour quenching and hydrolysis of fluorescent substrates.

Three organisms were identified on each 96-well microtitre plate. For each organism 32 biochemical tests adopted for identification were grouped in eight sets of four tests, and variations in test results within each of eight sets of tests were used to generate an eight digit biocode for each organism tested.

Inocula were prepared in sterile distilled water from 24 hour cultures on MacConkey agar (CM 7; Oxoid). Inocula were adjusted to a turbidity equivalent to a 0.5 McFarland standard and checked by the use of a nephelometer integral to the autoinoculator system. Fifty microlitres of inoculum were dispensed into each of 32 wells of the identification plate and an oil overlay was automatically added to the appropriate wells using the microprocessor-driven autoinoculator. Plates were incubated at $37^{\circ} \mathrm{C}$ for 24 hours and read using the autoreader. Eight digit biocodes were recorded and stored by the associated microprocessor, and the Willcox probability and the identification interpretation generated from the identification database. An identification based on Willcox probabilities was recorded when test results were interpreted as yielding an excellent $(>0.95)$, good $(>0.85)$, or acceptable $(>0.75)$ probability of identification. A report of low selectivity was generated where a probability of less than 0.75 was calculated from the database for particular test results.

Probable acceptable identifications by the API 20E and the Sensititre system were compared. The API 20E reports of excellent, very good, good and acceptable identification were compared with those of the Sensititre. Very doubtful profiles generated by the API $20 \mathrm{E}$ system were treated as equivalent to low selectivity reports generated by the Sensititre system.

\section{Results}

IDENTIFICATION OF CLINICAL ISOLATES BY

API 20E SYSTEM

An acceptable, good, very good or excellent species identification was obtained with the API 20E system for $251(92 \%)$ of the isolates examined. These comprised seven major species (table 1) and included Escherichia coli $(\mathrm{n}=116)$, Citrobacter freundii $(\mathrm{n}=32)$, Proteus mirabilis $(\mathrm{n}=27)$, Enterobacter cloacae $(\mathrm{n}=25), \quad$ Klebsiella oxytoca $(\mathrm{n}=10)$, Serratia marcescens $(\mathrm{n}=12)$ and Acinetobacter calcoaceticus $(\mathrm{n}=8)$. Species identification was obtained for a further 21 isolates representing 13 different species. Twenty three isolates $(8 \%)$ generated doubtful profiles and were not identified to species level. In 18 of these isolates differential identifications suggested by the database indicated the probability that these organisms belonged to the KlebsiellaEnterobacter-Serratia group of the Enterobacteriaceae.

\section{COMPARISON OF IDENTIFICATION BY BOTH SYSTEMS (table 1)}

Of 251 isolates identified to species level by the API 20E system, the Sensititre Autoidentification system identified $208(83 \%)$ as the same species, five $(2 \%)$ as different species, and failed to identify $38(15 \%)$ with low discrimination recorded between species. In most of those 38 isolates which were not identified to particular species level by the Sensititre system, 35 $(92 \%)$ included those species suggested as the most probable identifications on Willcox probability, those species identified for individual isolates by the API $20 \mathrm{E}$ system. Most of these isolates were identified as species of the genera Klebsiella, Enterobacter, and Citrobacter by the API 20E system.

Among those species identified by the API $20 \mathrm{E}$ system as minor components within the bacterial isolates studied (21 isolates), both systems were less effective than with the more common species. Low discrimination between possible species identifications was given by seven of 21 (33\%) isolates with Sensititre; with four isolates Sensititre yielded a different identification than that obtained with API 20E. Isolates identified by API 20E as Pseudomonas maltophilia (n $=2$ ) and Klebsiella pneumoniae $(\mathrm{n}=2)$ were identified by Sensititre as Alcaligenes denitrificans $(n=2)$ and $E$

Table 1 Identification of 274 isolates of oxidase negative fermentative bacilli by API $20 E$ and the Sensititre Autoidentification System

\begin{tabular}{|c|c|c|c|c|c|}
\hline \multirow[b]{2}{*}{ API Identification (No of isolates) } & & \multicolumn{4}{|c|}{ Sensititre identification (No of isolates) } \\
\hline & & Same as API $20 E$ & $\begin{array}{l}\text { Different from } \\
A P I 20 E\end{array}$ & $\begin{array}{l}\text { Identification } \\
\text { by Sensititre } \\
\text { only }\end{array}$ & $\begin{array}{l}\text { Low discriminaton } \\
\text { No species } \\
\text { identification }\end{array}$ \\
\hline $\begin{array}{l}\text { Escherichia coli } \\
\text { Citrobacter freundii } \\
\text { Proteus mirabilis } \\
\text { Enterobacter cloaceae } \\
\text { Klebsiella oxytoca } \\
\text { Serratia marcescens } \\
\text { Acinetobacter calcoaceticus } \\
\text { Other species } \\
\text { Other isolates (low species discrimination) }\end{array}$ & $\begin{array}{r}116 \\
32 \\
27 \\
25 \\
10 \\
12 \\
8 \\
21 \\
23\end{array}$ & $\begin{array}{r}103 \\
22 \\
27 \\
19 \\
7 \\
12 \\
8 \\
10\end{array}$ & 4 & 9 & $\begin{array}{r}13 \\
10 \\
6 \\
2\end{array}$ \\
\hline
\end{tabular}


cloaceae $(\mathrm{n}=2)$, respectively.

Of the 23 isolates with which acceptable species identification was not obtained with the API 20E tests and database, 14 isolates also yielded a low discrimination between probable species identifications with the Sensititre system. With both systems the most probable species identifications generated from the respective databases were similar and there were often problems in discriminating between Klebisella spp, Enterobacter spp, and $C$ freundii.

An acceptable species identification was yielded by Sensititre for nine isolates which gave very doubtful profiles by the API $20 \mathrm{E}$ system. These included isolates identified as $C$ freundii $(\mathrm{n}=2), E$ cloaceae $(\mathrm{n}=2), K$ pneumoniae $(\mathrm{n}=1)$, and Escherichia coli $(\mathrm{n}=4)$. In each case this species identification was included among the most probable species identifications generated by the API 20E database.

COMPARISON OF TEST RESULTS IN BOTH SYSTEMS Eight substrates used in the differentiation of metabolism of different bacteria are incorporated in both identification systems. For each individual substrate the percentage disagreement between the two systems was determined for the 274 isolates; this varied between 2\% (arabinose, mannitol, and tryptophan deaminase) $5 \%$ (sucrose, urea), $10.5 \%$ (sorbitol), $12 \cdot 6 \%$ (citrate) and $14.3 \%$ (inositol).

Differences in inositol test results were recorded with 40 isolates: $C$ freundii $(\mathrm{n}=30), E$ cloaceae $(\mathrm{n}=$ $7), E$ coli $(\mathrm{n}=2)$ and Citrobacter diversus $(\mathrm{n}=1)$. Seventeen of these 40 isolates yielded a low discrimination result with Sensititre in the presence of an acceptable species identification by API 20E: these included $C$ freundii $(\mathrm{n}=12)$ and $E$ cloaceae $(\mathrm{n}=5)$.

Differences in citrate test results in the two systems were noted with 33 isolates: $C$ freundii $(\mathrm{n}=27), A$ calcoaceticus $(\mathrm{n}=3)$, and Providencia stuartii $(\mathrm{n}=3)$. Sixteen of these 33 strains yielded a low discrimination result with Sensititre in the presence of an acceptable species identification by API 20E. These strains included $C$ freundii $(\mathrm{n}=14)$ and $A$ calcoaceticus $(\mathrm{n}$ $=2$ ).

In a substantial number of these isolates showing differences in inositol and citrate test results, these differences were associated with a failure of the Sensititre System to provide an acceptable identifica- tion of $C$ freundii. $C$ freundii, however, always remained among those species that the Sensititre database suggested as a possible identification with low discrimination. In general, for those biochemical tests shared by the two identification systems, the results given by isolates of $C$ freundii in the two systems were the same. In view of this uniformity of test results in those shared tests those tests common to both systems seem to contribute little to the low discrimination of identification by Sensititre of those isolates acceptably identified as $C$ freundii by API $20 \mathrm{E}$.

\section{COMPARISON OF BIOTYPES/BIOCODES}

GENERATED FOR INDIVIDUAL SPECIES BY BOTH SYSTEMS

The number of biotypes (biocodes in Sensititre) generated for individual species and yielding acceptable species identification in the two systems is shown in table 2. For each of the four species examined, significantly more biocodes were produced by the Sensititre System than the API system. With all species except $E$ coli, the major biotype produced by the API $20 \mathrm{E}$ system accounted for over $50 \%$ of isolates of the species. With $E$ coli, the two major biotypes together accounted for $50 \%$ of isolates of the species. The major biotype recorded for each species with the Sensititre System accounted for a significantly smaller percentage of the isolates of any species, suggesting that this biotyping method might be able to provide a more sensitive discrimination between isolates, which could be particularly useful in epidemiological studies of these organisms.

\section{ASSESSMENT OF REPRODUCIBILITY OF SENSITITRE} BIOCODE

Six strains were used to assess the reproducibility of the Sensititre biocode by duplicate testing of each strain on five separate occasions (table 3 ).

All 10 identifications of each isolate yielded an acceptable identical species identification. Even with duplicate testing on the same microtitre plate with the same inoculum preparation, however, considerable variation within duplicates occurred. E cloaceae 326 gave the best result with identity recorded within four of five duplicates listed but variation was recorded between duplicate pairs.

Variation in biocode within and between duplicates

Table 2 Number of biotypes/biocodes and major biotypes/biocodes represented among major pathogens identified by API $20 E$ and Sensititre Autoidentification System

\begin{tabular}{|c|c|c|c|c|c|c|}
\hline \multirow[b]{2}{*}{ Organism } & \multicolumn{3}{|c|}{$A P I 20 E$} & \multicolumn{3}{|c|}{ Sensititre } \\
\hline & $\begin{array}{l}\text { No of } \\
\text { isolates }\end{array}$ & $\begin{array}{l}\text { No of } \\
\text { biotypes }\end{array}$ & $\begin{array}{l}\text { Major biotype } \\
\text { (\% of isolates) }\end{array}$ & $\begin{array}{l}\text { No of } \\
\text { isolates }\end{array}$ & $\begin{array}{l}\text { No of } \\
\text { biocodes }\end{array}$ & $\begin{array}{l}\text { Major biocode } \\
\text { (\% of isolates) }\end{array}$ \\
\hline $\begin{array}{l}\text { Escherichia coli } \\
\text { Citrobacter freundii } \\
\text { Proteus mirabilis } \\
\text { Enterobacter cloaceae }\end{array}$ & $\begin{array}{r}116 \\
32 \\
27 \\
25\end{array}$ & $\begin{array}{r}26 \\
5 \\
6 \\
5\end{array}$ & $\begin{array}{l}5144552(26) \\
1404572(53) \\
0736000(55) \\
3305573(68)\end{array}$ & $\begin{array}{r}103 \\
22 \\
27 \\
19\end{array}$ & $\begin{array}{r}45 \\
11 \\
11 \\
9\end{array}$ & $\begin{array}{l}\text { 39D94CC0 (32) } \\
\text { BADB4EC2 (36) } \\
\text { 68E005C4 (33) } \\
\text { 3AD97EDF (26) }\end{array}$ \\
\hline
\end{tabular}


Table 3 Reproducibility of Sensititre biocode in duplicate testing of six Enterobacteriaceae on five different occasions

\begin{tabular}{lllc}
\hline Organism (isolate No) & $\begin{array}{l}\text { Duplicates* giving } \\
\text { identical biocode }\end{array}$ & $\begin{array}{l}\text { No of biocodes recorded } \\
\text { among identical duplicates }\end{array}$ & $\begin{array}{l}\text { Total No of biocodes } \\
\text { recorded }\end{array}$ \\
\hline Escherichia coli $(315)$ & $1 / 5$ & - & 7 \\
Escherichia coli $(247)$ & $2 / 5$ & 3 & 5 \\
Escherichia coli $(314)$ & $3 / 5$ & 3 & 9 \\
Enterobacter cloaceae (303) & $1 / 5$ & 3 & 4 \\
Enterobacter cloaceae (326) & $4 / 5$ & - & 5 \\
Serratia marcescens (207) & $0 / 5$ & & \\
\hline
\end{tabular}

* Results are comprised as a ratio of number of identical duplicates in a total of five duplicates.

resulted in many different biocodes being recorded among the 10 individual tests of each species examined.

\section{Discussion}

The Sensititre Autoidentification System is a fully automated system comprising inoculating, reading, data storage and retrieval facilities. The system also includes a capacity for determining minimum inhibitory concentrations of antibiotics.

This system identified to the same species $83 \%$ of isolates identified to species level by the API $20 \mathrm{E}$ system. Where species identification by API 20E was accompanied by low selectivity of identification by Sensititre, or where low selectivity of identification was common to both systems, both systems invariably included species of Klebsiella, Enterobacter, Serratia or Citrobacter in their individual differential species identification. Problems associated with discrimination among strains belonging to this group have been notoriously difficult to resolve. ${ }^{12}$

The examination of results recorded by both systems for those substrates which were included in both, showed that considerable variation for individual substrates occurred. These variations were seen particularly with $C$ freundii and $E$ cloaceae with the inositol and citrate substrates. Differences in test results for these substrates were associated with low selectivity of identification by the Sensititre System in many cases. Variation in these test results alone was not sufficient to account for low selectivity results, however, because positive or negative results for both inositol or citrate could be associated with acceptable identifications by the Sensititre database of $C$ freundii or $E$ cloaceae. There is, indeed, no essential requirement for some tests to yield the same results in different systems because thresholds for distinguishing positive or negative tests may differ between systems which detect changes by different methods.

An examination of biocodes generated for Sensititre for individual species showed that many more species biocodes could be generated than with API 20E. This discrimination of types could be of considerable value in population studies and as an epidemiological tool, but poor reproducibility with the current system makes this facility of little value at present.

Data generated by the system either as identification of Gram negative facultative bacilli or as minimum inhibitory concentrations may be stored on a hard disc. Accumulated data can be interrogated by the database software. Individual species can be recovered from the database with their ward distribution or antibiotic sensitivity to provide epidemiological information. The Digital PRO 380 microcomputer handling the Sensititre data can be interfaced with other laboratory computer systems and can become an intrinsic part of a laboratory reporting and surveillance system.

The cost of individual identifications by the two systems do not differ greatly, but the need for a substantial capital expenditure to provide the necessary Sensititre hardware is an important consideration. None the less, the system is easy to use and can readily be integrated into the working of a busy laboratory. The current system will evolve, as other systems have done, with wider use and regular updating, and reappraisal of the database will increase the percentage of clinical isolates of bacteria acceptably identified with the system. The sensitivity of the system may require substantial re-evaluation before biocode finger-printing can be offered by the system.

We acknowledge the help of Mrs C McIlhatton in the preparation of this paper.

References

1 Appelbaum PC, Arthur RR, Parker ME, Shugar GL, von Kuster LC, Charache P. Comparison of three methods for identification of Enterobacteriaceae. Eur J Clin Microbiol 1982;1:76-81.

2 Hayek LJ, Willis GW. Identification of the Enterobacteriaceae: a comparison of the Enterotube II with the API 20E. J Clin Pathol 1984;37:344-7.

3 Holmes B, Humphry PS. Identification of Enterobacteriaceae with the Minitek system. J Appl Bacteriol 1988;64:151-61.

4 Gavini F, Husson MO, Izard D, Bernigaud A, Quiviger B. Evaluation of Autoscan-4 for identification of members of the family Enterobacteriaceae. J Clin Microbiol 1988;26:1586-8.

5 Cornaglia G, Dainelli B, Berlutti F, Thaller MC. Commercial identification systems often fail to identify Providencia stuartii. J Clin Microbiol 1988;26:323-7.

6 Staneck JL, Vincelette J, Lanothe E, Polk EA. Evaluation of the Sensititre system for the identification of Enterobacteriaceae. $J$ Clin Microbiol 1983;17:647-54.

Requests for reprints to: Dr J G Barr, Department of Bacteriology, Royal Victoria Hospital, Belfast BT12 6BA. 